\title{
Metáfora e metonímia como mecanismo de variação lexical em Apurinã (Aruák)
}

\author{
Metaphor and metonymy as a mechanism of lexical variation \\ in Apurinã (Aruák)
}

\section{Bruna de Lima-Padovani}

Sidi Facundes

Universidade Federal do Pará - UFPA - Belém - Pará - Brasil

\begin{abstract}
Resumo: O presente trabalho visa apresentar os resultados de um estudo que busca descrever e analisar os processos metafóricos e metonímicos que subjazem a variação lexical em Apurinã, uma língua da família linguística Aruák. Os dados utilizados neste trabalho foram coletado in locus entre os anos de 2013 e 2015, junto a várias comunidades Apurinã, além de dados de pesquisa anteriores (FACUNDES 2000, BARRETO 2007 e BRANDÃO 2007). O estudo se articula no quadro teóricometodológico da Teoria da Metáfora Conceptual (LAKOFF e JOHNSON, 1980) e da Sociolinguística Variacionista (LABOV, 2008 [1972]). Os casos de variação lexical tratados aqui envolvem principalmente a nomenclatura de fauna e flora que constituem o fenômeno do "duplo vocabulário" (uso extensivo de duas ou mais formas para designar um mesmo referente em um domínio específico do léxico da língua) presente na língua. Os resultados indicam que o fenômeno de "duplo vocabulário" existente na língua permite fazer inferências sobre a organização conceitual que os falantes têm de certos elementos de fauna e flora. O fato de o "duplo vocabulário" apresentar uma coerência semântica construída a partir das relações metafóricas e metonímicas que motivam nomear dois referentes com a mesma forma sugere haver uma rede semântica interligando referentes distintos no léxico Apurinã.
\end{abstract}

Palavras-chave: Metáfora. Metonímia. Variação Lexical. Apurinã

\begin{abstract}
This paper presents the results of a study that seeks to describe and analyze the metaphorical and metonymic processes underlying lexical variation in Apurinã, a language of the Arawak language family. The data used in this study were collected in locus between the years 2013 and 2015, with a number of Apurinã communities, and previous research data (FACUNDES 2000 BARRETO 2007 and BRANDÃO 2007). The study is articulated theoretical and methodologically in the frameworks of Conceptual Metaphor Theory (LAKOFF and JOHNSON, 1980) and Variationist Sociolinguistics (LABOV, 2008 [1972]). Cases of lexical variation treated here mainly involve the naming of flora and fauna that make up the phenomenon of "double vocabulary" (extensive use of two or more ways to designate a same referent in a specific field of language lexicon) in this language. The results indicate that the phenomenon of "double vocabulary" existing in the language allows for inferences about the conceptual organization that speakers have of certain elements of fauna and flora. The fact that the "double vocabulary" presents semantic consistency built from metaphorical and metonymic relations that motivate the naming of two referents by the same form suggests the existence of an interconnected semantic network in the Apurinã lexicon.
\end{abstract}

Keywords: Metaphor. Metonymy. Lexical Variation. Apurinã. 


\section{Introdução}

Apurinã é uma etnia indígena e uma língua minoritária, pertencente ao ramo Purus da família linguística Aruák; é falada em comunidades espalhadas ao longo de vários tributários do rio Purus, no sudeste do Estado do Amazonas, e em comunidades ao longo da rodovia 317, que liga as cidades do Rio Branco e Boca do Acre (FACUNDES, 2000). Há também um número bastante significativo de Apurinã vivendo fora das aldeias, principalmente nas periferias das cidades de Lábrea (AM), Pauini (AM), Tapauá (AM), Boca do Acre (AM), Jatuarana (AM) e Rio Branco (AC) e alguns vivendo com etnias Tupí em Rondônia (LIMA e FACUNDES, 2014).

O tópico do presente trabalho faz parte de uma pesquisa bem mais ampla sobre os processos envolvidos na formação das variantes da língua Apurinã. Temos como objetivos principais (i) identificar todos os casos de variantes lexicais que compõem o "duplo vocabulário", (ii) descrever e analisar os fatores (linguísticos e extralinguísticos) que motivam o uso de duas ou mais formas lexicais para nomear o mesmo referente, e (iii) e examinar a relevância desses fatores para a teoria linguística. Nosso foco são especificamente os padrões metafóricos e metonímicos que estão por trás da variação lexical.

O artigo está organizado em cinco seções, além da introdução. Na primeira, são fornecidas as principais ideias da Teoria da Metáfora Conceitual, proposta por Lakoff e Johnson; na segunda, encontrase a metodologia empregada no desenvolvimento deste trabalho; na terceira, discute-se acerca da variação Lexical e do "duplo vocabulário" em Apurinã; na quarta, são apresentados os processos de categorização de fauna e flora Apurinã, assim como os fenômenos que estão por traz da variação lexical existentes na língua; na quinta, são feitas algumas considerações sobre a relevância e contribuição de nossos resultados para os estudos da variação linguística em Apurinã e sua relevância para a teoria linguística.

\section{Metáfora e metonímia}

O campo de pesquisa em metáfora e metonímia recebeu um enorme impulso com o surgimento da teoria de mapeamentos conceituais (LAKOFF E JOHNSON 1980, LAKOFF 1987, JOHNSON 1987, LAKOFF E TURNER 1989, LAKOFF 1993). Com o intuito de detalhar essa nova perspectiva em relação a metáfora e metonímia, esta seção busca traçar um panorama geral das principais contribuições referentes ao assunto, a fim de preparar terreno, delimitando algumas noções básicas para tudo que será discutido nas seções subsequentes.

\subsection{Metáfora}

A tese básica de Lakoff e Johnson (1980) sobre metáfora é que a sua função nos permite interpretar conceitos abstratos em termos de conceitos familiares e de experiências cognitivas cotidianas; ou seja, a metáfora está presente em toda parte e é essencial na linguagem e no pensamento. Nesse sentido, a compreensão de mundo passa a ser vinculada à concepção da metáfora, uma vez que grande parte dos conceitos básicos, como tempo, quantidade, estado e ação, além dos conceitos emocionais, como raiva e amor, são compreendidos metaforicamente. Isso evidencia o importante papel da metáfora na compreensão do mundo e da cultura.

Segundo Lakoff e Johnson (1980) ${ }^{1}$ a metáfora é, essencialmente, um mecanismo que envolve a conceptualização de um domínio de experiência em termos de outro. $O$ entendimento da metáfora se daria por meio de buscas de similaridades entre termos comparados. Para cada metáfora, é possível identificar um domínio-fonte (aquele a partir do qual conceitualizamos alguma coisa metaforicamente) e um domínio-alvo (aquele que desejamos conceitualizar). Para os autores, o domínio-fonte

\footnotetext{
1 The source domain is assumed to be structured by a propositional or image-schematic model. The mapping is typically partial; it maps the structure in the source domain onto a corresponding structure in the target domain. As we mentioned above, the source and target domains are represented structurally by CONTAINER schemas, and the mapping is represented by a SOURCE-PATH-GOAL schema.
} 
implica propriedades físicas e áreas relativamente concretas da experiência; por sua vez, o domínio-alvo tende a ser mais abstrato ou mais especifico, dependendo da situação.

Segundo Lakoff (1987, p. 288, tradução nossa) ${ }^{3}$, as relações feitas entre os domínios (fonte e alvo) são conduzidas por um mapeamento metafórico em que:

o domínio-fonte é estruturado por um modelo proposicional ou uma imagem esquemática. $\mathrm{O}$ mapeamento é tipicamente parcial; mapeia a estrutura do domínio-fonte para uma estrutura correspondente no domínio-alvo. Os domínios fonte e alvo são representados estruturalmente por esquemas de contentores, e o mapeamento é representado por um esquema de fonte-caminho-meta

A metáfora é uma representação mental (existe na mente e atua no pensamento). Elas refletem a ideologia e o modo de ver o mundo de um grupo de pessoas em uma determinada cultura. Em outras palavras, as metáforas são os resultados do desenvolvimento histórico-cognitivo dos indivíduos na busca de compreender o mundo ao redor.

\subsection{Metonímia}

Tradicionalmente a metonímia é definida como deslocamento de significado, no qual uma palavra que normalmente é utilizada para designar determinada entidade passa a designar outra. De acordo com Lakoff e Johnson (1980) metonímia é um fenômeno da referência indireta em que um signo linguístico substitui ou identifica outro referente. Para definir metonímia, além de outros tipos de referência indireta, como metáfora ou ironia, clássicos retóricos a definem como uma troca de nomes para as coisas que são intimamente relacionadas ou juntas.

Segundo Hilpert (2006), diversas tipologias de metonímia (STERN 1931, LAKOFF e JOHNSON 1980, FASS 1997, KÖVECSES e RADDEN 1998) listam a presença da contiguidade nas relações. Nesse sentido, o autor faz uma distinção entre dois tipos básicos: O primeiro tipo abrange todas as relações de contiguidade entre uma entidade e suas partes. Relações de contiguidade deste tipo serão chamado E-metonímias. O segundo tipo inclui as relações de contiguidade que obtêm entre categorias e subcategorias, tal relação de contiguidade será chamada de C-metonímias. Em suma, E-metonímias são "parte-de" relações enquanto C-metonímias são "espécie de" relações. O Quadro 1 apresenta o que Hilpert (2006) chama de taxonomia das relações metonímicas que são ilustrados pelos exemplos (1-6):

Quadro 1: Taxonomia das relações metonímicas ${ }^{2}$

\begin{tabular}{|lll|}
\hline E-Metonímia & $\begin{array}{l}\text { Parte por Inteiro } \\
\text { Inteiro por parte } \\
\text { Parte por parte }\end{array}$ & $\begin{array}{l}\text { Face por pessoa (1) } \\
\text { Lugar por instituição (2) } \\
\text { Objeto usado pelo usuário (3) }\end{array}$ \\
& & \\
Metonímia & Super. por Sub. & Pessoa genérica por pessoa específica (4) \\
& $\begin{array}{l}\text { Sub. por Super. } \\
\text { Sub. por Sub. }\end{array}$ & $\begin{array}{l}\text { Marca específica por produto genérico (5) } \\
\text { Període de tempo específico por outro } \\
\text { período de tempo específico (6) }\end{array}$ \\
& &
\end{tabular}

Fonte Hilpert, 2006, p. 133

\section{Exemplos de E-Metonímias}

(1) Precisamos de novas caras por aqui.

(2) Paris está introduzindo saias mais longas nesta estação.

(3) Os ônibus estão em greve.

\section{Exemplos de C-Metonímias}

(4) Agora que ele foi promovido, ele realmente acha que é alguém.

(5) Você pode me dar uma fita Durex?

(6) Me dá um segundo.

Lakoff e Turner (1989 apud FERRARI, 2011) sugerem que a projeção metonímica envolve só um domínio, fator que o distingue da metáfora que se dá entre dois domínios. Croft (1993 apud FERRARI, 2011) afirma que a "metonímia promove o realce de um domínio especifico no âmbito de um domíniomatriz complexo e abstrato". Portanto, a metonímia coloca em destaque a informação relevante à

\footnotetext{
${ }^{2}$ No original os dados estão em inglês, portanto as traduções para o português são de nossa autoria.
} 
caracterização enciclopédica do domínio-matriz em um determinado contexto.

\section{Procedimentos metodológicos}

Antes de descrevermos os dados linguísticos da língua Apurinã a serem analisados neste trabalho, vamos a alguns procedimentos metodológicos dos quais fizemos uso. Os instrumentos metodológicos utilizados nesta pesquisa incluíram um levantamento sociolinguístico que se baseia no modelo de análise dos estudos variacionistas (LABOV, 2008 [1972]) e nos métodos da linguística de corpus (BAIBER, CONRAD e REPEPEN, 1988).

Primeiramente fizemos a constituição do corpus, que inclui dados disponíveis coletados em pesquisas anteriores e compilados no programa computacional FLEx. A partir dele, elaboramos uma lista de palavras onde constavam termos dos campos semânticos de fauna e flora que apresentavam formas variantes para designar o mesmo conceito. Em seguida, partimos para o trabalho de campo com o intuito de expandir e verificar os dados já coletados, além de descobrir os fatores motivadores para a ocorrência do fenômeno de "duplo vocabulário".

Um segundo momento, foi dedicado à identificação, análise e discussão dos fatores motivadores para o uso do "duplo vocabulário", entre eles identificamos os padrões metafóricos e metonímicos. Como veremos abaixo, esses fenômenos se mostraram importantes para a compreensão dos processos de categorização de fauna e flora Apurinã.

\section{Variação lexical e o duplo vocabulário apurinã}

A variação lexical em Apurinã envolve palavras cujas formas são completamente distintas umas das outras. Os casos de variação lexical tratados aqui envolvem principalmente a nomenclatura de fauna e flora que compõe o que denominamos de "duplo vocabulário" da língua. Segundo Lima (2013), o "duplo vocabulário" consiste em itens lexicais que apresentam aparente sinonímia em que mais de uma palavra é usada para referir-se ao mesmo elemento conceitual.

No primeiro trabalho com foco em variação linguística em Apurinã, Barreto (2007) afirma que há três tipos gerais de variação lexical mais comuns nessa língua. A primeira é a variação geracional, que é representada por variantes distintas usadas em um mesmo espaço por indivíduos de faixas etárias diferentes, a exemplo do conceito para 'sucurijú': kiãty para os mais velhos e kapinhuty para os mais novos. A segunda é a variação geográfica, que é representada por aquelas formas que têm suas variantes distribuídas em comunidades distintas, como, por exemplo, o conceito para 'japó', reconhecido em algumas comunidades como iũpiri, mas como pukuru(ru) em outras. Finalmente, a terceira é a variação geográfico-geracional, que se caracteriza pela ocorrência de uma variação geracional em diferentes comunidades geográficas. Nesta última, uma variante que pode ter uma distribuição geográfica restrita, também aparece restrita a uma faixa etária específica. Como exemplo desse tipo de variação podemos considerar o caso da palavra para "macaco-de-cheiro", que é reconhecida por três formas: amãtxuary, ipỹte e xariwa. A forma amãtxuary está restrita a algumas comunidades, caracterizando aí uma variação geográfica; porém, mesmo nessas comunidades, essa forma encontra-se restrita a uma faixa etária específica, pois é uma forma antiga, usada somente pelos mais idosos, o que caracterizaria também nessas comunidades a variação geracional.

Diferentes membros de uma mesma comunidade podem reconhecer e utilizar ativamente mais de uma variante, mas jamais todas aquelas fazem parte do "duplo vocabulário". Ou seja, as variantes em Apurinã não estão associadas exclusivamente a um grupo ou outro, isto é, um falante usa uma variante com relativa frequência, podendo reconhecer uma ou outra forma em função do contato com falantes de variedades distintas da mesma língua. No segundo caso, trata-se de um conhecimento passivo, em que o falante pode 
reconhecer (ao escutar ou ser perguntado sobre) duas ou mais variantes de uma mesma palavra, mas jamais usar mais de uma delas. Esse conhecimento muiltidialetal está associado ao constante movimento migratório e consequente contato e interação entre indivíduos de diferentes comunidades Apurinã.

O fato das comunidades Apurinã estarem distribuídas ao longo dos tributários do rio Purus, apresentando uma larga extensão geográfica entre si, torna favorável o desenvolvimento de um grau significativo de variação na língua. Em virtude deste distanciamento as diferentes comunidades passaram por experiências distintas, sofrendo influências diferentes na apropriação de determinados conceitos, a maneira como tais comunidades "nomeiam" a realidade que as cercam acaba por convergir para o uso de formas diferentes para se referir a um mesmo conceito. Isto é, falantes de comunidades diferentes optaram por estratégias variadas para nomeá-los. Como veremos abaixo, algumas diferenças importantes nessas estratégias estão relacionadas a distintos padrões metafóricos e metonímicos adotados por diferentes comunidades.

A próxima seção, se dedicará a explicar como se dá o processo de categorização de fauna e flora Apurinã. Veremos como os Apurinã classificam esses elementos e de que modo essa classificação influencia no processo de variação, além de descrevermos como os fenômenos metafóricos e metonímicos operam nesse processo.

\section{Categorização da terminologia de fauna e flora apurinã}

A construção do significado envolve vários aspectos, entre eles uma construção mental, em um movimento contínuo de categorização e recategorização do mundo, a partir da interação de estruturas cognitivas e modelos compartilhados de crenças socioculturais (FERRARI, 2011). Isto é, o significado convencionalmente associado às palavras são abstrações a partir de uma vasta gama de contextos de uso associados a um dado item lexical.

Em Apurinã o processo de denominação da nomenclatura de fauna e flora não implica apenas uma simples associação entre elementos e palavras, mas consiste na formação de um sistema de compreensão construído a partir de sua propensão em associar um símbolo a uma representação mental que leva em consideração padrões comportamentais, funcionais, características físicas e os sons produzidos pelos animais. Segundo Cruse (2001), tais padrões se diferenciam da taxonomia científica, que se constitui apenas em similaridades e diferenças físicas dos elementos. Para o autor a taxonomia tradicional é mais detalhista que a científica.

Cruse (2011) afirma que a taxonomia tradicional é um sistema em que grupos populares são relacionados por inclusão hierárquica e podem não seguir sistemas 'regulares', o que explica a maior gradualidade do sistema tradicional e menor gradualidade do sistema científico.

Para Cruse (2011) a taxonomia tradicional tem ao menos três níveis hierárquicos: um nível superordenado, um nível básico, e um nível subordinado. Como exemplo, temos: um animal como superordenado, uma ave como termo básico e uma coruja como um elemento subordinado. No Quadro 2 apresentaremos as estratégias de categorização dos Apurinã.

\begin{tabular}{|c|c|c|c|}
\hline \multirow{2}{*}{$\begin{array}{l}\text { Nome em } \\
\text { Português }\end{array}$} & \multicolumn{3}{|c|}{ Nome em Apurinã } \\
\hline & Superordenado & $\begin{array}{c}\text { Básico } \\
\text { (genérico) }\end{array}$ & Subordinado \\
\hline 1 abelha & $\begin{array}{l}\text { amapyty } \\
\text { 'qualquer } \\
\text { abelha' }\end{array}$ & $\begin{array}{l}\text { mapa 'abelha } \\
\text { que produz } \\
\text { mel' }\end{array}$ & $\begin{array}{l}\text { ixiri ‘abelha } \\
\text { arapuá pequena' } \\
\text { ĩxitanaky 'abelha } \\
\text { de padre' } \\
\text { xũnũnu 'abelha } \\
\text { preta' kaseruĩiru } \\
\text { 'abelha jandaira' } \\
\text { pumamaĩru } \\
\text { 'ususu' }\end{array}$ \\
\hline 2 aranha & - & $\begin{array}{l}\text { katsakituru } \\
\text { 'caranguejeir } \\
\text { a' }\end{array}$ & $\begin{array}{l}\text { katsakituru } \\
\text { 'caranguejeira' } \\
\text { merïtxi 'aranha } \\
\text { que gruda no pau } \\
\text { - isca para pegar } \\
\text { matrinchã' } \\
\text { xuakyru 'aranha } \\
\text { pequena' }\end{array}$ \\
\hline 3 banana & - & txipari & $\begin{array}{l}\text { kỹpaty 'banana } \\
\text { brava' } \\
\text { ithupekare } \\
\text { 'banana baié' } \\
\text { kanũtxi 'banana } \\
\text { comprida' } \\
\text { kunuxu 'banana } \\
\text { roxa' }\end{array}$ \\
\hline $\begin{array}{l}4 \text { bicho de } \\
\text { casco }\end{array}$ & - & - & $\begin{array}{l}\text { sỹpyry 'tartaruga' } \\
\text { xutui 'jabuti' } \\
\text { maiauru } \\
\text { 'matamata' } \\
\text { txikype }\end{array}$ \\
\hline
\end{tabular}




\begin{tabular}{|c|c|c|c|}
\hline & & & $\begin{array}{l}\text { 'cabeçuda' } \\
\text { kunhiru 'tracajá' }\end{array}$ \\
\hline 5 caba & - & sany & $\begin{array}{l}\text { ãpũtasany- } \\
\text { 'caba chapéu' } \\
\text { ximiri 'caba } \\
\text { grande' } \\
\text { kasyrysãny 'caba } \\
\text { cega' } \\
\text { kimitiri 'caba } \\
\text { surubim' }\end{array}$ \\
\hline 6 cipó & - & aãpytsa & $\begin{array}{l}\text { aãpytsa 'cipó } \\
\text { titica' } \\
\text { purutsa 'cipó } \\
\text { titica' } \\
\text { xĩpytsa 'cipó } \\
\text { ambé' } \\
\text { tunytsa 'cipó de } \\
\text { tracuá' } \\
\text { katxipukyry 'cipó } \\
\text { de tracuá' } \\
\text { pupetetsaru 'cipó } \\
\text { chato' }\end{array}$ \\
\hline 7 cobra & - & ymyny & $\begin{array}{l}\text { kapinhuty } \\
\text { 'sucurijú' } \\
\text { kamũpyry 'cobra } \\
\text { cega' } \\
\text { apataputy 'cobra } \\
\text { coral' } \\
\text { kukuipi 'cobra } \\
\text { papagaio' } \\
\text { kasurury } \\
\text { 'surucucu' }\end{array}$ \\
\hline 8 coruja & - & $\begin{array}{l}\text { musa 'coruja } \\
\text { caboré' }\end{array}$ & $\begin{array}{l}\text { musa 'coruja } \\
\text { caboré' } \\
\text { musakyry 'coruja- } \\
\text { orelhuda - } \\
\text { espécie de coruja } \\
\text { branca' } \\
\text { peru 'coruja } \\
\text { menor que a } \\
\text { musa' } \\
\text { ũty 'corujão' } \\
\text { awapyru 'coruja } \\
\text { grande' }\end{array}$ \\
\hline 9 formiga & - & katxipukyry & $\begin{array}{l}\text { Katxipukyry } \\
\text { 'tracuá' } \\
\text { aiuãke 'taioca' } \\
\text { mukytu 'taioca } \\
\text { branca' } \\
\text { kanãii 'formiga de } \\
\text { fogo que fica no } \\
\text { taxizeiro' } \\
\text { matyke 'formiga } \\
\text { de fogo pequena' } \\
\text { mãiaaru 'formiga } \\
\text { de fogo que fica } \\
\text { na capoeira' } \\
\text { katxity 'sauva' } \\
\text { manhĩi } \\
\text { 'tucandeira' } \\
\text { tarakuwa tracuá' }\end{array}$ \\
\hline \multirow[t]{2}{*}{10 fruta } & $\begin{array}{l}\text { amãteery 'todo } \\
\text { tipo de fruta' }\end{array}$ & $\begin{array}{l}\text { txipukury } \\
\text { 'fruta que } \\
\text { come' }\end{array}$ & $\begin{array}{l}\text { anãna 'abacaxi' } \\
\text { xipari 'banana' } \\
\text { kuwĩri 'melancia' } \\
\text { maky 'castanha' } \\
\text { txupata 'goiaba } \\
\text { araçá' } \\
\text { iũpate 'caju' } \\
\text { îkawary 'tucumã' } \\
\text { ĩpỹtykãpi 'abiu' } \\
\text { kawyry 'pupunha' }\end{array}$ \\
\hline & $\begin{array}{l}\text { iri 'quando ainda } \\
\text { está na árvore' }\end{array}$ & $\begin{array}{l}\text { ĩthupakyri } \\
\text { 'fruta do } \\
\text { mato' }\end{array}$ & $\begin{array}{l}\text { iuyky 'castanha } \\
\text { de cutia' } \\
\text { matakury 'coco } \\
\text { de anta' }\end{array}$ \\
\hline 11 felinos & - & ãkiti 'onça' & $\begin{array}{l}\text { ãkiti kaiũkari } \\
\text { 'onça pintada' } \\
\text { ãkiti pumamary } \\
\text { 'onça preta' } \\
\text { ãkiti pukamamary } \\
\text { 'onça vermelha' } \\
\text { ãkiti 'gato } \\
\text { maracajá' } \\
\text { ãkitiawĩthe 'gato' }\end{array}$ \\
\hline 12 inseto & - & $\begin{array}{l}\text { maiãnitxi } \\
\text { 'inseto que } \\
\text { ferra' }\end{array}$ & $\begin{array}{l}\text { kaxipiru 'lacraia' } \\
\text { aiuãke 'taioca' } \\
\text { mukytu 'taioca } \\
\text { branca' } \\
\text { sany 'caba' }\end{array}$ \\
\hline
\end{tabular}

\begin{tabular}{|c|c|c|c|}
\hline & & - & $\begin{array}{l}\text { tsupata 'barata' } \\
\text { aũtynaky } \\
\text { 'varejeira' } \\
\text { xikiry 'mosca' } \\
\text { txipiw 'besouro } \\
\text { cascudo' }\end{array}$ \\
\hline 13 jacaré & - & kaykyry & $\begin{array}{l}\text { kaykyry 'jacaré } \\
\text { açu' } \\
\text { makapia 'Jacaré } \\
\text { preto' }\end{array}$ \\
\hline 14 lagarta & - & kaxatu & $\begin{array}{l}\text { awaíky- lagarta } \\
\text { que fica no } \\
\text { buraco do bueiro } \\
\text { sanhikinhi 'lagarta } \\
\text { que dá na árvore } \\
\text { do patauá' } \\
\text { kixuru 'lagarta } \\
\text { que anda de } \\
\text { bando } \\
\text { kerutaky" } \\
\text { katxiketu" } \\
\text { xiuwai 'lagarta } \\
\text { que dá na } \\
\text { paxiuba' }\end{array}$ \\
\hline 15 macaco & - & $\begin{array}{l}\text { txikuty } \\
\text { 'macaco } \\
\text { prego' }\end{array}$ & $\begin{array}{l}\text { txikuty 'macaco } \\
\text { prego' } \\
\text { mapiruwa } \\
\text { 'macaco prego } \\
\text { grande' } \\
\text { itxikyry 'macaco } \\
\text { preto' } \\
\text { kuã 'macaco } \\
\text { zogue-zogue' } \\
\text { wexupire 'macaco } \\
\text { janau' } \\
\text { xariwa 'macaco } \\
\text { xeiro' } \\
\text { txuaryky 'macaco } \\
\text { soim' }\end{array}$ \\
\hline 16 macaxeira & - & iumyary & $\begin{array}{l}\text { uanary } \\
\text { 'caboquionha' } \\
\text { kaseruparu 'olho } \\
\text { verde' mandioca } \\
\text { branca } \\
\text { putxuãky } \\
\text { 'mandioca cheia } \\
\text { d'água' } \\
\text { kynary } \\
\text { 'macaxeira } \\
\text { amarela' } \\
\text { makure 'macoré' } \\
\text { 'macaxeira vara' }\end{array}$ \\
\hline 17 morcego & - & xiiu 'morcego' & $\begin{array}{l}\text { ãpukyry 'morcego } \\
\text { pequeno' } \\
\text { mapukyry } \\
\text { 'morcego grande' } \\
\text { upukary 'morcego } \\
\text { grande' }\end{array}$ \\
\hline 18 passarinho & - & kutypyryky & $\begin{array}{l}\text { tuwakyru 'sabiá' } \\
\text { pirũty 'beija-flor' } \\
\text { txikary 'alma-de- } \\
\text { gato' } \\
\text { txiupyra 'piador, } \\
\text { adivinhão' } \\
\text { ypỹtykyry 'bem-ti- } \\
\text { vi' } \\
\text { sukury 'bico-de- } \\
\text { brasa' }\end{array}$ \\
\hline 19 peixe & - & ximaky & $\begin{array}{l}\text { amakyry } \\
\text { tambaqui' } \\
\text { mamury } \\
\text { 'matrinxã' } \\
\text { (h)uma 'piranha' } \\
\text { iukara 'peixe- } \\
\text { agulha' } \\
\text { tsukurima } \\
\text { 'surubim' } \\
\text { wasa 'pacu com } \\
\text { pintas vermelhas' } \\
\text { kapixikury 'piau } \\
\text { quati' }\end{array}$ \\
\hline 20 rato & - & kyyryky & $\begin{array}{l}\text { kyyryky 'rato } \\
\text { pequeno' } \\
\text { tanare 'rato coro' } \\
\text { kutxi 'rato de } \\
\text { casa' }\end{array}$ \\
\hline 21 sapo & - & patxiri & $\begin{array}{l}\text { atyneru 'sapo } \\
\text { grande' } \\
\text { ase 'sapo-boi' }\end{array}$ \\
\hline
\end{tabular}

Signo [ISSN 1982-2014]. Santa Cruz do Sul, v. 41, n. 70, p. 64-74, jan./jun. 2016. 


\begin{tabular}{|l|l|l|}
\hline & & durua 'um tipo de \\
& sapo que dá para \\
& comer' \\
awyru'sapo \\
canuaru' \\
tsakakaru 'sapo' \\
kura 'sapo \\
pequeno; sapo \\
folha' \\
uãdury 'um tipo \\
de sapo' \\
arytũpa \\
'motocozinho, \\
sapo pequeno' \\
\hline
\end{tabular}

Observamos que em Apurinã há poucos nomes relativos ao nível superordenado, o que está de acordo com o que propõem Berlin (1992). Segundo o autor os itens que pertencem ao nível superordenado geralmente não são nomeados. Isso ocorre em virtude de a semelhança entre seus membros ser baixa (FERRARI, 2011). Neste nível atestamos apenas 3 termos em Apurinã: amapyty 'qualquer abelha', amãtyyry, 'todo tipo de fruta' e iri 'todo tipo de fruta que ainda está na árvore'.

Em relação ao nível básico (ou genérico), estes são mais comuns em Apurinã, a exemplo temos: mapa 'abelha que produz mel'; txipari 'banana', sany 'caba', ymyny 'cobra', txipukury 'fruta que se come', ĩthupakyri 'fruta do mato', ãkiti 'onça', maiãnhitxi 'inseto que ferra', kaxatu 'lagarta', umyary 'macaxeira', kutypyryky 'passarinho', e ximaky 'peixe'. Verificamos que os falantes normalmente percebem os termos do nível básico como os verdadeiros nomes dos referentes. Esses termos costumam ser nomes simples e não são criados como extensões metafóricas a partir de outros domínios.

Ainda em relação aos termos básicos observamos que há membros no interior de uma categoria com características especiais que estão organizados em termos de uma escala de prototipicidade. O protótipo é considerado o melhor exemplo de uma categoria. Uma única imagem mental representa toda a categoria. Ou seja, o membro de uma classe pode representar a classe inteira. Como exemplo de membros prototípicos em Apurinã temos: katsakituru 'aranha caranguejeira', aãpytsa 'cipó titica', musa 'coruja caburé', katxipukyry 'tracuá', txikuty 'macaco prego', macaxeira 'iumyary', xiiu 'morcego', kyyryky 'rato', patxiri 'sapo'. Portanto, temos aqui casos de metonímia em que a classe é representada por um de seus membros.

É preciso ressaltar, entretanto, que o elemento mais prototípico de uma categoria também pode depender do contexto. Alguns indivíduos representam certas propriedades categoriais de forma diferente em diferentes contextos. Estas podem estar relacionadas às experiências individuais e ao contexto cultural que os indivíduos e uma determinada sociedade estão imersos. Em parte, isso explicaria a variação linguística em Apurinã.

Atestamos também que em Apurinã as propriedades semânticas das unidades lexicais derivam de seu duplo estatuto de denominação; isto é, da possibilidade de designar um conceito a partir de dois parâmetros distintos, pois o sentido descritivo de um termo não deriva apenas de propriedades semânticas dos seus referentes, mas também das determinações que the são conferidas pelo uso ou pela sua relação com outros termos do sistema lexical. Observamos a ocorrência de pares com sentidos descritivos ${ }^{3}$ vs. sentidos não descritivos para a terminologia de fauna e flora, o que influencia diretamente na formação das variantes lexicais na língua. Estas, em geral, são motivadas por padrões metafóricos e metonímicos. No Quadro 3, apresentaremos exemplos da ocorrência desses pares e em seguida analisaremos os padrões metafóricos e metonímicos como sendo uma das operações cognitivas utilizadas pelos falantes de Apurinã no processo de categorização.

Quadro 3: Formas descritivas vs. não descritiva.

\begin{tabular}{|l|l|l|}
\hline \multirow{2}{*}{$\begin{array}{c}\text { Nome em } \\
\text { Português }\end{array}$} & $\begin{array}{l}\text { Nome em Apurinã } \\
\text { Descritivo }\end{array}$ & $\begin{array}{l}\text { Sentido de } \\
\text { Descritivo }\end{array}$ \\
\cline { 2 - 3 } 1. onça preta & ãkiti pumamary & ãkiti mapiãnyry \\
\hline 2. café & kapẽe & kỹpatykỹã \\
\hline 3. cavalo; burro & kawaru & Ixiwãwithe \\
\hline
\end{tabular}

\footnotetext{
${ }^{3}$ Nomes que fazem registros da maneira como os usuários de uma língua compõem ou utilizam os elementos no seu dia-adia.
} 


\begin{tabular}{|c|c|c|}
\hline \multirow[t]{2}{*}{ 4. porco domestico } & \multirow{2}{*}{$n / a$} & Mititiãwithe \\
\hline & & Iraryãwithe \\
\hline \multirow[t]{2}{*}{ 5. carneiro } & \multirow{2}{*}{$n / a$} & Manitiawithe \\
\hline & & sutyawithe \\
\hline $\begin{array}{l}\text { 6. quatipuru } \\
\text { roxinho }\end{array}$ & axipitiri & ãkiti tikakiẽrike \\
\hline 7. piau quati & puwana & Kapixikury \\
\hline 8. tamanduaí & apasawatary & Kamyrikĩ \\
\hline \multirow[t]{2}{*}{ 10. cipó timbó açu } & \multirow[t]{2}{*}{ iapetsa } & Ixiwanynytsa \\
\hline & & Itumanerutsa \\
\hline 11. mané-magro & kunusury & Aãke \\
\hline 12. cipó de tracuá & tũnytsa & Katxipukyrytsa \\
\hline $\begin{array}{l}\text { 13. canapu/ } \\
\text { camapu }\end{array}$ & mutumutuky & Kytsynapunitikyte \\
\hline 14. gato maracajá & putxukary; ãkiti & Txuwiriẽne \\
\hline 15. taioca & aiuãke & tũtiii \\
\hline 16. farinha & parĩa & Katarukyry \\
\hline
\end{tabular}

No item 1, no primeiro termo, os falantes da língua levam em consideração a cor do animal ãkiti pumamary (o nome pumamary corresponde à cor preta). Já o segundo termo ãkiti mapiãnyry está ligado ao hábito noturno do animal, pois o nome mapiãnyry está semanticamente relacionado ao nome mapiã que corresponde a escuridão, noite. Ou seja, enquanto no primeiro caso a nomeação baseia-se numa descrição física, no segundo ela se baseia numa descrição do comportamento do animal (hábitos noturnos).

No item 2, a forma kỹpatykỹã é usada para designar 'café' e também parece ser uma extensão de sentido do conceito kỹpaty, que é a forma para nomear 'bananeira brava'. Isso acontece em virtude de kỹpaty ter uma semente preta que se parece com a semente do café; ou seja, os Apurinã adotaram traços da similaridade física de kỹpaty (dominio-fonte) para nomear o conceito 'café' (dominio-alvo).

No item 3, a forma ixiwãwithe, usada para conceituar o elemento 'cavalo', é constituída por ixiwa (tamanduá bandeira) + ãwithe (chefe). Podemos observar o mesmo fenômeno no quarto e no quinto item do quadro. No entanto, observamos que em algumas comunidades os falantes optaram por uma estratégia diferente para nomear estes conceitos. Por exemplo, no item 4, a forma iraryãwithe, usada para designar 'porco doméstico' parte do termo para 'queixada (Tayassu pecarı)'; porém, outros falantes da língua usaram o termo miritiãwithe, que é a forma para nomear 'porquinho (Pecari tajacu)'. Por sua vez, no item 5, as formas para designar 'carneiro' provêm dos termos sutyãwithe 'veado roxo' e manitiãwithe 'veado da capoeira'.

Em 6, a forma ãkiti tikakiẽrike está relacionada ao aspecto da barriga do animal, a qual tem pintas que se parecem com as pintas da onça pintada; por isso essa forma recebe o mesmo nome da onça. Portanto, a motivação de usar o nome que normalmente designa 'onça' para designar também 'quatipuru roxinho' é o mapeamento de propriedades físicas da 'onça' (domínio fonte) a propriedades físicas da barriga do 'quatipuru' (domínio alvo). Outro dado que merece atenção acerca desse item é que um dos consultores Apurinã relatou também que esse animal se alimenta dos dejetos da onça e por isso esse animal receberia o mesmo nome da onça. Nesse caso, teríamos um processo de variação cuja motivação é reforçada pelos padrões metonímicos entre os dois elementos, - o fato de o 'quatitupu' alimentar-se dos dejetos produzidos pela 'onça'; ou seja, o conceito 'quatipuru' seria nomeado pelo nome do animal que produz o alimento que ele costuma consumir.

No item 7, também é levado em consideração o aspecto do animal que possui listas iguais a do rabo do 'quati' kapixi. Observa-se que o processo de variação ocorre motivada pela metáfora, uma vez que há o mapeamento de propriedades físicas do 'quati' (domínio fonte) a propriedades físicas do 'piau' (domínio alvo).

O termo kamyrikĩ do item 8 deriva do nome kamyry, forma que designa 'espírito', uma vez que esse animal, segundo relatado pelos Apurinã, some na mata como um espírito. Nota-se que neste item o 
mapeamento é feito a partir de propriedades comportamentais do dominio-fonte 'espirito'. Vale ressaltar, que o tamanduaí representa também na cultura Apurinã um sinal de que haverá morte na família quando ele é visto na mata.

No item 9, observamos que a segunda forma ixiwanynytsa (ixiwa = tamanduá bandeira' + nyny $=$ língua $+t s a=$ nome classificatório para coisas finas e alongadas) que designa 'cipó timbó-açu' está relacionada ao aspecto da língua do 'tamandua bandeira'. De acordo com os colaboradores a forma achatada e alongada do cipó parece com a língua do 'tamandua bandeira'. Outro dado importante acerca desse item é que itumanerutsa nome que também designa o 'cipó timbo-açu', segundo relatos dos colaboradores Apurinã, corresponde ao cipó usado pelo chefe dos queixadas. Ou seja, essa forma estaria relacionada à função que o cipó exerce na cultura Apurinã.

Em 10, verificamos que a segunda forma aãke (aã - 'planta' + ke = nome classificatório para coisas finas e flexíveis) que designa 'vara' também pode ser usado para nomear o 'manéu-magro' ou 'bicho pau'. Nota-se que para este item a motivação dos falantes nomearem este animal com o mesmo nome que designa 'vara' é o mapeamento das propriedades físicas do domínio fonte 'vara' ao domínio alvo 'manéu-magro', já que este tem o corpo parecido com uma 'vara'.

Os itens 11 e 12 estão associados à função que eles exercem na cultura Apurinã. A forma katxipukyrytsa (Katxipukyry = 'tracuá' + tsa $=$ nome classificatório para coisas finas e alongadas ) 'cipó de tracuá' está relacionada à função que o cipó tem para as formigas. Segundo relatos dos consultores, as formigas utilizam o cipó para construir sua casa. $O$ mesmo acontece com o item 13, onde a forma kytsynapunitikyte (kytsyna = 'calango' + punitikyte = 'pimenta') significa literalmente a pimenta do calango, o que sugere ser 'canapu/camapu' alimento desse animal. Observa-se que a variação lexical para este conceito ocorre motivada por padrões metonímicos, 'camapu' (fruta silvestre que cresce em roçados após a queimada) é nomeado pelo nome do animal que costuma se alimentar dessa fruta. Nota-se que a variação é reforçada também por padrões metafóricos, uma vez que, para a constituição desse nome os falantes se basearam nas propriedades físicas da pimenta 'punitikyte' (dominio-fonte).

Em 14, a forma txuwiriẽne está semanticamente relacionada ao nome txuirikaru que designa 'nambu relógio'. Segundo relatos dos Apurinã o 'gato maracajá' costuma imitar o som que o 'nambu relógio' produz com o propósito de capturar o pássaro para se alimentar.

No item 15, a forma tũtĩi está relacionada ao hábito do jacu, uma vez que esse pássaro se alimenta de restos de pequenos insetos deixados pela formiga 'taioca'. Nota-se que o processo de variação ocorre motivado por padrões metonímicos entre os dois elementos, uma vez que a 'taioca' é chamada pelo nome do animal que se beneficia dos restos dos seus alimentos.

Verificamos no item 16, que a variante katarukyry, deriva de kataruky, um termo usado para designar uma espécie de 'roça de macaxeira' e que também é matéria-prima para a produção de farinha. O termo nativo em Apurinã para 'farinha' surgiu a partir da extensão de sentido da forma kataruky, uma vez que antigamente não existia farinha, apenas beiju, na cultura tradicional Apurinã. Atestamos que neste caso a variação ocorre motivada pela metonímia, uma vez que o termo para farinha surge a partir do nome da sua matéria prima.

A partir dessa análise, podemos afirmar que o fenômeno do "duplo vocabulário" pode ser descrito como a expressão de um sistema de compreensão das relações entre conceitos que participam do universo sociocultural Apurinã, portanto de uma realidade extralinguística que permite ao falante criar e recriar palavras, e atribuir novos significados a palavras já existentes.

Observamos também que o "duplo vocabulário" apresenta uma coerência semântica construída a partir das relações metafóricas, metonímicas e pragmático-funcionais que motivam nomear dois referentes distintos com a mesma forma. Tal coerência sugere haver uma rede semântica (e talvez 
pragmática) interligando referentes distintos no léxico Apurinã, revelando a visão do mundo dos falantes, no que se refere aos elementos de fauna e flora.

\section{Considerações Finais}

Este trabalho apresentou os processos metafóricos e metonímicos envolvidos na formação do "duplo vocabulário" presente na língua Apurinã, no que diz respeito ao domínio da fauna e flora Apurinã. Procuramos demostrar, a partir da discussão teórica juntamente com a análise acima, que os padrões metafóricos e metonímicos, são fenômenos essenciais na variação da taxonomia indígena tradicional pelos quais são criadas as nomenclaturas para a fauna e flora. Observamos que as categorias, utilizadas pelos Apurinã para a compreensão da sua realidade, resultam da forma pela qual elas são organizadas em suas mentes, experienciadas e pela interação com a cultura em que estão inseridos.

Pudemos observar também que as unidades lexicais que constituem o "duplo vocabulário" estão presente no raciocínio metafórico dos falantes que procuram ancorar a compreensão de algo novo naquilo que é experienciado por eles. Ou seja, conceitos concretos são mobilizados para entendimento, explanação e descrição de um fenômeno menos concreto.

Verificamos, ainda, que as metáforas e as metonímias em Apurinã interagem entre si, gerando um sistema complexo. Esse sistema se caracteriza pela existência de um domínio fonte $\mathbf{A}$, considerado bem estruturado e o domínio alvo $\mathbf{B}$, que precisa ser estruturado para uma compreensão mais detalhista do conceito. A ligação entre os elementos envolvidos é feita por meio de mapeamentos (LAKOFF e JOHNSON, 1980). Esses mapeamentos são naturalmente motivados através da correlação estrutural existente entre os dois domínios, isto é, da existência de traços comuns entre ambos.

A partir dos resultados preliminares desse estudo, podemos afirmar que o fenômeno do "duplo vocabulário" pode ser descrito como a expressão de um sistema de Apurinã, portanto de uma realidade extralinguística, neste caso, a cosmologia Apurinã, que permite ao falante criar e recriar palavras, e atribuir novos significados a palavras já existentes. Essas relações evidenciam o quanto a interação é significativa e influencia no processo de formação das variantes linguísticas. De fato ela desempenha papel fundamental nos atos comunicativos, visto que a língua se concretiza a partir do ambiente contextual de realização.

Os limites entre os elementos são definidos pelo observador, em outras palavras, pelos falantes da língua Apurinã. No entanto, dito isso, concluímos também que o fenômeno do "duplo vocabulário" para a fauna e flora Apurinã é mais que um sistema de variação lexical. É, na verdade, um sistema de taxonomia tradicional extremamente dinâmico em que alguns elementos dessa classificação são referidos e até classificados de formas aparentemente distintas, porém em pleno acordo com o Modelo Cognitivo ou/e Cultural em que ele se encaixa dentro da sociedade, cultura, história e cosmovisão Apurinã.

\section{Referências}

BAIBER, Douglas; CONRAD; Susan. REPEPEN; Randi. Corpus Linguistic: Investigating Language Structure and Use. Cambridge: MIT Press, 1988. BARRETO, Érica Lúcia. Variação em Apurinã:
Aspectos linguísticos e Condicionantes. Tese de mestrado. Universidade Federal do Pará. Belém: 2007.

BRANDÃO, Ana Paula B. Dicionário da Língua Apurinã. Belém, 2006. Trabalho de Conclusão de Curso (Licenciatura em Língua Portuguesa). Departamento de Letras e Literaturas Vernáculas, Universidade Federal do Pará, Belém.

CRUSE, Alan. Meaning in Language: An Introduction to Semantics and Pragmatics. Oxiford Linguistcs. New York, 2000.

DEIGNAN, Alice: Corpus-based Approaches to Metaphor and Metonymy. In Anatol Stefanowitsch, Stefan Th. Gries. The grammar of linguistic metaphors. Mouton de Gruyter Berlin - New York, 2006. P. 106-122 
FACUNDES, Sidney da Silva. 2000. The language of the Apurinã people of Brazil (Maipure/Arawak). Buffalo: University of New York.

FERRARI, Lilian. Introdução à Linguística Cognitiva. São Paulo: Contexto.

HILPERT, Martin. Corpus-based Approaches to Metaphor and Metonymy. In Anatol Stefanowitsch, Stefan Th. Gries. Keeping and eye on the data: Metonymies and their patterns. Mouton de Gruyter Berlin. New York. 2006. P. 123-151

LABOV. William. Padrões Sociolinguístico. BAGNO, Marcos; SCHERRE, Maria Marta Pereira; CARDOSO, Caroline Rodrigues (trad.). São Paulo: Parabóla, 2008.

LAKOFF, George; JOHNSON, Mark. Metaphors We Live By. Chicago and London: The University of Chicago. 1980

LAKOFF, George. Women, fire, and dangerous things. Chicago: The University of Chicago. 1987

LIMA, Bruna Fernanda S. Variação, Mudanças e o "Duplo Vocabulário" na Língua Apurinã (Aruák). Belém, 2013. Trabalho de Conclusão de Curso (Licenciatura em Língua Portuguesa). Instituto de Letras e Comunicação, Universidade Federal do Pará, Belém.

LIMA, Bruna Fernanda S.; FACUNDES, Sidi. 'O Duplo Vocabulário' e a Variação Lexical na Língua Apurinã (Aruák). In: ABRALIN EM CENA AMAZONAS, 2014, Manaus. ABRALIN EM CENA AMAZONAS ANAIS. Manaus: UEA Edições, 2014. v. 1. p. 149-161. 